\title{
POLA ASUH ORANG TUA DAN PERKEMBANGAN ANAK PRA SEKOLAH
}

\author{
Raihana Norfitri
}

\author{
Program Studi Diploma Tiga Keperawatan Stikes Intan Martapura, Indonesia \\ Email : rnorfitri@gmail.com
}

\begin{abstract}
ABSTRAK
Anak prasekolah yang berusia 3-6 tahun mempunyai perkembangan kemampuan berbahasa, kreativitas, kesadaran sosial, emosional dan intelegensia yang berkembang sangat cepat, sehingga peran orang tua penting dalam pembentukan perkembangan mental maupun psikologis anak seperti pola asuh. Pola asuh yang kurang tepat berdampak pada keterlambatan perkembangan anak yang tidak optimal hanya satu ranah perkembangan saja, atau dapat pula di lebih dari satu ranah perkembangan. Penelitian ini telah mengetahui apakah ada hubungan antara pola asuh orang tua dengan perkembangan anak pra sekolah di Paud Terpadu Nurul Ma'arifah Desa Tunggul Irang Ilir Martapura. Penelitian ini menggunakan jenis penelitian deskriptif korelasi dengan pendekatan cross sectional, dengan populasi 52 orang jumlah sampel 52 orang dengan teknik sampel yang digunakan adalah total sampling. Instrumen yang digunakan dalam penelitian ini adalah kusioner. Pengumpulan data dengan menggunakan data primer dan sekunder. Analisis data univariat dengan tekhnik asosiatif dan bivariat menggunakan uji chi-square. Didapatkan hasil ada hubungan (significant) antara pola asuh orang tua dengan perkembangan anak pra sekolah di Paud Terpadu Nurul Ma'arifah Desa Tunggul Irang Ilir Martapura
\end{abstract}

\section{Kata Kunci $\quad$ : pola asuh, perkembangan, anak pra sekolah}

\section{ABSTRACT}

Preschool children aged 3-6 years have the development of language skills, creativity, social awareness, emotional and intelligence that develop very quickly, so the role of parents is important in the formation of children's mental and psychological development such as parenting. Inappropriate parenting has an impact on children's developmental delays that are not optimal in only one developmental domain, or can also be in more than one developmental domain. This study has found out whether there is a relationship between parenting patterns and the development of pre-school children in Nurul Ma'arifah Integrated Early Childhood Education, Tunggul Irang Ilir Martapura Village. This study uses a descriptive correlation research with a cross sectional approach, with a population of 52 people with a sample of 52 people with the sample technique used is total sampling. The instrument used in this research is a questionnaire. Data collection using primary and secondary data. Univariate data analysis using associative and bivariate techniques using chi-square test. The results showed that there was a significant relationship between parenting patterns and the development of pre-school children in Nurul Ma'arifah Integrated Early Childhood Education, Tunggul Irang Ilir Martapura Village.

\section{Key Words: parenting, development, pre-school children}

Cite this as : $\quad$ Norfitri, R. (2021). Pola Asuh Orang Tua dan Perkembangan Anak Pra Sekolah. Jurnal Ilmu Kesehatan Insan Sehat, 9(1), 15-19.

\section{PENDAHULUAN}

Pembangunan kesehatan melalui upaya peningkatan kesehatan anak perlu diterapkan sedini mungkin sejak masih dalam kandungan sampai dengan lima tahun pertama kehidupan. Hal ini bertujuan untuk memelihara kelangsungan hidup sekaligus meningkatkan kualitas hidup anak untuk mencapai perkembangan yang baik dari segi pertumbuhan fisik, mental, emosional dan sosial yang optimal sehingga anak memiliki kecerdasan pluralistik berdasarkan potensi genetiknya (Festivia, 2019; Dahlan, 2011).

Keluarga merupakan bagian yang berperan terpenting dalam tumbuh kembang anak dan membentuk persepsi anak untuk berinteraksi dengan 
dunia, sehingga berpengaruh pada pengembangan kompetensi sosial dan identitas diri pada anak prasekolah (Golovei et.all, 2015). Para ahli menyebut usia pra sekolah sebagai masa keemasan perkembangan (golden age), dan didapatkan lebih dari 200 miliar anak di negara berkembang tidak mampu mencapai perkembangan yang potensial (Kemendiknas, 2011).

Data Departemen kesehatan RI dalam penelitian (Widati, 2012) didapatkan sebanyak 0,4 juta (16\%) balita di Indonesia mengalami gangguan tumbuh kembang, baik motorik halus, motoric kasar, gangguan pendengaran, tingkat kecerdasan kurang serta keterlambatan bicara. Berdasarkan data Dinas Kesehatan dalam (Widati, 2012) sebesar 85.779 $(62,02 \%)$ anak usia prasekolah mengalami gangguan perkembangan. Sekitar 5 hingga 10\% anak diperkirakan mengalami keterlambatan perkembangan. Data kejadian keterlambatan perkembangan secara umum belum diketahui pasti, namun diperkirakan sekitar 1-3\% anak di bawah usia 5 tahun mengalami keterlambatan perkembangan umum (IDAI, 2013).

Tingginya angka gangguan perkembangan pada anak usia prasekolah disebabkan berbagai faktor. Pola asuh orangtua menjadi faktor yang mendasari dalam tumbuh kembang anak. Pola asuh diidentifikasi menjadi tiga, yaitu pola asuh otoriter, otoritatif dan permisif. Hasil penelitian menyatakan bahwa anak yang di asuh dengan otoritatif membuat anak menjadi mandiri, dapat bersosialisasi positif dengan teman sebaya dan memilik rasa percaya diri. Sedangkan permisif membuat anak menjadi manja, kurang percaya diri dan gampang frustasi (Juniari, 2014). Berdasarkan fenomena yang telah dipaparkan, peneliti tertarik untuk melakukan penelitian terkait pola asuh orangtua terhadap gangguan perkembangan pada anak usia prasekolah.

\section{METODE}

Desain penelitian ini deskriptif korelasi dengan pendekatan cross sectional.Populasi berjumlah 52 siswa dengan teknik sampel yang digunakan yaitu total sampling.

Pengumpulan data menggunakan wawancara kepada seluruh ibu yang mempunyai anak pra sekolah yang ada di di Paud Terpadu Nurul Ma'arifah Desa Tunggul Irang Ilir dengan menggunakan instrument kuesioner. Analisis data menggunakan distribusi frekuensi. Hasil uji statistik dengan menggunakan uji deskriftif.

\section{HASIL}

Karakteristik responden yang terdiri dari umur, pendidikan dan pekerjaan ibu dan anak dapat dilihat pada Tabel 1.
Raihana Norfitri, Pola Asuh Orang Tua dan Perkembangan

Tabel 1 : Distribusi Frekuensi Berdasarkan Karakteristik Responden di PAUD

\begin{tabular}{|c|c|c|}
\hline Karakteristik & $\mathbf{N}$ & $\%$ \\
\hline \multicolumn{3}{|l|}{ Umur } \\
\hline 17-25 Tahun & 11 & 21,2 \\
\hline 26-35 Tahun & 33 & 63,5 \\
\hline 36-45 Tahun & 8 & 15,4 \\
\hline \multicolumn{3}{|l|}{ Pendidikan } \\
\hline SLTP & 10 & 19,2 \\
\hline SLTA & 29 & 55,8 \\
\hline PT & 13 & 25 \\
\hline \multicolumn{3}{|l|}{ Pekerjaan } \\
\hline IRT & 30 & 57,7 \\
\hline Swasta & 21 & 40,4 \\
\hline PNS & 1 & 1,9 \\
\hline \multicolumn{3}{|l|}{ Umur Anak } \\
\hline 4 Tahun & 13 & 25 \\
\hline 5 Tahun & 21 & 40,4 \\
\hline 6 Tahun & 18 & 34,6 \\
\hline
\end{tabular}

Berdasarkan Tabel 1 karakteristik responden berdasarkan umur terbanyak pada rentang umur $26-35$ tahun 33 responden $(63,5 \%)$ Pendidikan terbanyak SLTA $29(55,8 \%)$ dan pekerjaan terbanyak sebagai IRT 30 responden $(57,7 \%)$ dan umur anak terbanyak 5 tahun 21 responden $(40,4 \%)$

Pola asuh orang tua yang terdiri dari otoriter,situasional dan demokratis dapat dilihat pada Tabel 2. Dari Tabel 2 dapat dilihat pola asuh terbanyak adalah otoriter sebanyak 20 responden $(38,5 \%)$

\section{Tabel 2 : Distribusi Frekuensi Pola Asuh Orang}

\begin{tabular}{llc}
\hline \multicolumn{1}{c}{ Pola Asuh } & $\mathrm{N}$ & $\%$ \\
\hline Otoriter & 20 & 38,5 \\
Situasional & 18 & 34,6 \\
Demokratis & 14 & 26,9 \\
$\quad$ Total & $\mathbf{5 3}$ & $\mathbf{1 0 0}$
\end{tabular}

Pola asuh orang tua dapat dilihat pada Tabel 2. Pola asuh otoriter 20 responden (38,5\%), situasional 18 responden $(76,9 \%)$, dan demokratis 38 responden $(73,1 \%)$

Tabel 3 : Distribusi Frekuensi Perkembangan Anak Pra Sekolah

\begin{tabular}{ccc}
\hline Variabel & Frekuensi & Persentase \\
Perkembangan & & \\
\hline Motorik Kasar & & \\
Normal & 40 & $76,9 \%$ \\
Resiko & 12 & $23,1 \%$ \\
Terlambat & 0 & $0 \%$ \\
Motorik Halus & & \\
Normal & 46 & $88,5 \%$ \\
Resiko & 6 & $11,5 \%$ \\
Terlambat & 0 & $0 \%$ \\
Sosialisasi & & \\
Normal & 38 & $73,1 \%$ \\
\hline
\end{tabular}

http://jurnalstikesintanmartapura.com/index.php/jikis 


\begin{tabular}{ccc}
\hline $\begin{array}{c}\text { Variabel } \\
\text { Perkembangan }\end{array}$ & Frekuensi & Persentase \\
\hline Resiko & 14 & $26,9 \%$ \\
Terlambat & 0 & $0 \%$ \\
Bahasa & & \\
Normal & 38 & $73,1 \%$ \\
Resiko & 14 & $26,9 \%$ \\
Terlambat & 0 & $0 \%$ \\
\hline
\end{tabular}

Dari tabel dapat dilihat perkembangan motoric kasar terbanyak dengan kategorik normal 40 responden (76,9\%), motoric halus terbanyak dengan kategorik normal 46 responden $(88,5 \%)$, sosialisasi dengan kategorik normal terbanyak 38 responden $(73,1 \%)$ dan Bahasa dengan kategori terbanyak 38 responden $(73,1 \%)$

Tabel 5: Hubungan Pola Asuh Orang Tua dengan Perkembangan Motorik Kasar Anak Prasekolah

\begin{tabular}{|c|c|c|c|}
\hline \multirow{2}{*}{ Pola Asuh } & \multicolumn{2}{|c|}{ Motorik Kasar } & \multirow{2}{*}{ Total } \\
\hline & Normal & Resiko & \\
\hline Otoriter & $\begin{array}{c}20 \\
(38,5 \%)\end{array}$ & $0(0 \%)$ & $20(38,5 \%)$ \\
\hline Situasional & $\begin{array}{c}12 \\
(21,1 \%)\end{array}$ & $6(11,5 \%)$ & $18(34,6 \%)$ \\
\hline Demokratis & $\begin{array}{c}8 \\
(15,4 \%)\end{array}$ & $6(11,5 \%)$ & $14(26,9 \%)$ \\
\hline
\end{tabular}

$\mathrm{P}=0,002 \mathrm{p}<\alpha(5 \%)$, Correlation Coefficient $(0,427)$

Hubungan pola asuh orang tua dengan perkembangan motoric kasar dapat dilihat pada Tabel 5 . Dari Tabel 5 hubungan pola asuh orang tua dengan perkembangan motoric kasar dengan pola asuh otoriter dan motoric kasar anak yang terbanyak normal 20 responden $(38,5 \%)$

Tabel 6: Hubungan Pola Asuh Orang Tua dengan Perkembangan Motorik Halus Anak Pra Sekolah

\begin{tabular}{|c|c|c|c|}
\hline \multirow{2}{*}{ Pola Asuh } & \multicolumn{2}{|c|}{ Motorik Halus } & \multirow{2}{*}{ Total } \\
\hline & Normal & Resiko & \\
\hline \multirow{2}{*}{ Otoriter } & 20 & $0(0 \%)$ & 20 \\
\hline & $(38,5 \%)$ & & $(38,5 \%)$ \\
\hline \multirow{2}{*}{ Situasional } & 17 & $1(1,9 \%)$ & 18 \\
\hline & $(32,7 \%)$ & & $(34,6 \%)$ \\
\hline \multirow{2}{*}{ Demokratis } & 9 & $5(9,6 \%)$ & 14 \\
\hline & $(17,3 \%)$ & & $(26,9 \%)$ \\
\hline \multirow{2}{*}{ Total } & 40 & 12 & 52 \\
\hline & $(76,9 \%)$ & $(23,1 \%)$ & $(100 \%)$ \\
\hline $\begin{array}{l}P=0,002 \\
(0,418)\end{array}$ & $\alpha(5 \%)$ & Corrlation & oefficient \\
\hline
\end{tabular}

Tabel 6 hubungan pola asuh orang tua dengan perkembangan motoric halus dengan pola asuh otoriter dan motoric kasar anak yang terbanyak normal sebanyak 20 responden $(38,5 \%)$
Tabel 7 : Hubungan Pola Asuh Orang Tua dengan Perkembangan Sosialisasi Anak Pra Sekolah

\begin{tabular}{|c|c|c|c|}
\hline \multirow{2}{*}{ Pola Asuh } & \multicolumn{2}{|c|}{ Sosialisasi } & \multirow{2}{*}{ Total } \\
\hline & Normal & Resiko & \\
\hline Otoriter & $18(34,6 \%)$ & $2(3,8 \%)$ & $\begin{array}{c}20 \\
(38,5 \%)\end{array}$ \\
\hline Situasional & $14(26,9 \%)$ & $4(7,7 \%)$ & $\begin{array}{c}18 \\
(34,6 \%)\end{array}$ \\
\hline Demokratis & $6(11,5 \%)$ & $8(15,4 \%)$ & $\begin{array}{c}14 \\
(26,9 \%)\end{array}$ \\
\hline Total & $40(73,1 \%)$ & $12(26,9 \%)$ & $\begin{array}{c}52 \\
(100 \%)\end{array}$ \\
\hline $\mathrm{P}=0,003 \mathrm{p}$ & o), Corrlatio & efficient $(0$ & \\
\hline
\end{tabular}

Hubungan pola asuh anak dengan hubungan perkembangan sosialisasi anak pra sekolah dapat dilihat pada Tabel 7. Dari Tabel 7 pola asuh orang tua dengan perkembangan sosialisasi dengan pola asuh anak yang terbanyak otoriter normal sebanyak 18 responden $(34,6 \%)$

Tabel 8 : Hubungan Pola Asuh Orang Tua dengan Perkembangan Bahasa Anak Pra Sekolah

\begin{tabular}{|c|c|c|c|}
\hline \multirow{2}{*}{ Pola Asuh } & \multicolumn{2}{|c|}{ Bahasa } & \multirow{2}{*}{ Total } \\
\hline & Normal & Resiko & \\
\hline Otoriter & $20(38,5 \%)$ & $0(0 \%)$ & $20(38,5 \%)$ \\
\hline Situasional & $12(23,1 \%)$ & $6(11,5 \%)$ & $18(34,6 \%)$ \\
\hline Demokratis & $6(11,5 \%)$ & $8(15,4 \%)$ & $14(26,9 \%)$ \\
\hline Total & $40(73,1 \%)$ & $12(26,9 \%)$ & $52(100 \%)$ \\
\hline \multicolumn{4}{|c|}{$\mathrm{P}=0,003 \mathrm{p}<\alpha(5 \%)$, Corrlation Coefficient $(0,406)$} \\
\hline
\end{tabular}
perkembangan bahasa anak pra sekolah dapat dilihat pada Tabel 8. Dari Tabel 8 hubungan pola asuh anak dengan perkembangan bahasa anak pra sekolah normal dengan terbanyak otoriter 20 responden $(38,5 \%)$.

\section{PEMBAHASAN}

Pola asuh orang tua di gambarkan sebagai interaksi antara anak dan orang tua dalam kegiatan pengasuhan. Menurut Tarsis Tarmuji (2009), pengasuhan yang tidak tepat berpengaruh pada keterlambatan perkembangan pada anak. Keterlambatan perkembangan umum atau global developmental delay merupakan keadaan keterlambatan perkembangan yang bermakna pada dua atau lebih ranah perkembangan (IDAI, 2013).

Hasil penelitian yang telah dilakukan kepada 52 responden di PAUD Terpadu Nuru Ma'arifah tentang pola asuh orang tua mayoritas berada pada kategori pola asuh otoriter yaitu sebanyak 20 orang $(38,5 \%)$. Menurut Dariyo (2011), pada pola asuh otoriter anak dituntut menaati peraturan maupun perkataan orang tua. Apabila anak membantah, orang tua tidak segan-segan akan memberi hukuman, biasanya berupa hukuman fisik. Hal ini tentu berdampak negatif pada psikologis 
dan fisik anak tersebut yang dapat menghambat pertumbuhan dan perkembangan anak.

Pengetahuan yang rendah dapat diatasi dengan memberikan pendidikan tentang pola asuh orang tua terhadap anak, hal ini dikarenakan salah satu peran aktif orang tua adalah mengasuh anak. Pola asuh merupakan gambaran interaksi sikap dan perilaku orang tua kepada anak. Kemampuan interpersonal dan mengendalikan emosional diperlukan untuk memberikan rasa nyaman pada anak agar kemandirian anak meningkat.

Hasil penelitian yang telah dilakukan kepada 52 responden di PAUD Terpadu Nuru Ma'arifah tentang perkembangan motorik kasar anak pra sekolah mayoritas berada pada ketegori Normal yaitu sebanyak 40 orang $(76,9 \%)$. Motorik kasar merupakan bagian dari aktivitas motorik berupa keterampilan otot-otot besar, gerakan ini menuntut kekuatan fisik dan keseimbangan, gerakan motorik kasar melibatkan aktivitas otot tangan, kaki, dan seluruh anggota tubuh, serta mengandalkan kematangan dalam koordinasi (Agus, 2011).

Masa pra sekolah memiliki berbagai tugas perkembangan yang harus terpenuhi sebelum mencapai tahap perkembangan selanjutnya. Tekanan yang berlebihan ataupun pengharapan yang terlalu tinggi melampaui kapasitas kemampuan anak membuat anak memilih untuk berbohong atau berbuat curang agar dapat diterima oleh kelompok sosial anak. Hal ini menjadi salah satu penyebab terjadinya hambatan dalam perkembangan anak.

Pada masa pra sekolah perkembangan kemampuan berbahasa, kreativitas, kesadaran sosial, emosional dan intelegensia berjalan sangat cepat merupakan landasan perkembangan berikutnya, sehingga peran keluarga sangat penting untuk memberikan rangsangan atau menstimulus perkembangan anak secara optimal dan menyeluruh meliputi pendidikan, pengasuhan, kesehatan, gizi, dan perlindungan karena perkembangan anak berbeda satu sama lain yang dipengaruhi faktor internal maupun eksternal (Afandi,dkk, 2013). Anggota keluarga yang berperan penting dalam pembentukan perkembangan mental maupun psikologis pada anak adalah orang tua. Orang tua adalah pendidik pertama bagi anak-anak mereka, karena dari orang tualah anak mendapatkan pendidikan untuk pertama kalinya dan menjadi dasar bagi perkembangan anak dikemudian hari.

Hasil penelitian yang telah dilakukan kepada 52 responden di PAUD Terpadu Nuru Ma'arifah tentang perkembangan motorik halus anak pra sekolah
Raihana Norfitri, Pola Asuh Orang Tua dan Perkembangan mayoritas berada pada ketegori Normal yaitu sebanyak 46 orang $(88,5 \%)$. Motorik halus adalah gerakan yang menggunakan otot-otot halus atau sebagian anggota tubuh tertentu, yang dipengaruhi oleh kesempatan untuk belajar dan berlatih. Kedua kemampuan tersebut sangat penting agar anak bisa berkembang dengan optimal (Agus, 2011).

Hasil penelitian yang telah dilakukan kepada 52 responden di PAUD Terpadu Nuru Ma'arifah tentang perkembangan sosialisasi anak pra sekolah mayoritas berada pada ketegori Normal yaitu sebanyak 38 orang $(73,1 \%)$.

Perkembangan sosialisasi sangat luas dan berkaitan dengan perasaan anak terhadap diri sendiri serta hubungan dengan orang lain. Perkembangan ini mengacu pada perilaku dan respon interaksi anak dalam aktifitas bermain dan berkegiatan diluar, kedekatan dengan anggota keluarga, pengasuh, guru, maupun teman-teman. Keluarga dan nilai budayanya adalah pengaruh utama dalam membentuk perkembangan sosial anak dan ciri kepribadian dasar (Soetjiningsih, 2014).

Berdasarkan hasil penelitian yang telah dilakukan kepada 52 responden di PAUD Terpadu Nuru Ma'arifah tentang perkembangan bahasa anak pra sekolah mayoritas berada pada ketegori Normal yaitu sebanyak 38 orang $(73,1 \%)$.

Bahasa merupakan sebuah system simbol dilakukan secara lisan, maupun menggunakan pergerakan tubuh (seperti melambai, mengerutkan dahi, gemetar ketakutan), yang memudahkan untuk melakukan komunikasi satu sama lain. Perkembangan bicara dan bahasa sangat erat dengan perkembangan kognitif, sosial, perseptual serta sel otak anak. Perkembangan bahasa dan penggunaaannya dipengaruhi oleh jenis bahasa yang didengar oleh anak baik dirumah, sekolah maupun lingkungan masyarakat.

Perkembangan bahasa pada anak terjadi sistematis dan berkembang seiring dengan pertambahan usia anak. Idealnya perkembangan yang terjadi secara teratur, betahap dan menyesuaikan dengan kematangan dan adanya kesempatan belajar yang baik. Ketika berada pada tahun pertama kehidupan disebut fase pralinguistik atau prabahasa, dimana anak hanya bisa bergantung pada gerakan tubuh dan suara menangis dan tertawa untuk mengutarakan perasaannya. Pada tahun kedua memasuki fase linguistic yang mana anak sudah mulai berbicara untuk berkomunikasi walaupun belum terlalu jelas. Saat memasuki tiga atau empat tahun, kemampuan bahasa anak semakin berkembang, anak 
mulai belajar menyusun kata-kata membentuk kalimat sederhana yang diikuti kalimat gabungan yang dapat diterima dengan baik karena tata bahasa mulai tepat . (Soetjiningsih, 2014).

Berdasarkan hasil uji statistik dengan menggunakan uji spearman rank diperoleh nilai sig. (2teiled) lebih kecil dari 0,05 atau 0,01 maka artinya ada hubungan yang signifikan (berarti) antara pola asuh orang tua dengan perkembangan motorik kasar, motorik halus, sosialisasi dan Bahasa anak.

Pola asuh orang tua sangat penting dalam perkembangan anak (Tarsis Tarmudji, 2009). Semakin banyak pengalaman yang dimiliki, maka pengetahuan seseorang juga akan bertambah. Sehingga dengan pengalaman yang dimiliki oleh orang tua dapat membantu dalam mengasuh anak serta memenuhi kebutuhan anak secara optimal. Faktor lain yang dapat mempengaruhi perkembangan anak balita yaitu gizi, psikologis, sosial ekonomi, stimulasi, dan obat-obatan. Perkembangan pada masa balita sangat dipengaruhi oleh lingkungan dan pola asuh dari orang tuanya (Adriana, 2011). Kemampuan interpersonal dan pengendalian emosional juga sangat diperlukan orang tua untuk memberikan rasa nyaman pada anak. Sehingga dengan pola asuh yang tepat akan mempengaruhi tingkat kemandirian anak.

\section{KESIMPULAN}

1. Pola asuh orang tua di PAUD Terpadu Nurul Ma'Arifah mayoritas berada pada ketegori pola asuh otoriter yaitu sebanyak 20 orang $(38,5 \%)$

2. Perkembangan motorik kasar, motoric halus, sosialisasi dan bahasa anak pra sekolah di PAUD Terpadu Nurul Ma'Arifah mayoritas berada pada ketegori normal.

3. Berdasarkan hasil uji statistik dengan menggunakan uji spearman rank diperoleh nilai sig. (2-teiled) sebesar 0,002. Dengan demikian nilai sig. (2-teiled) 0,002 lebih kecil dari 0,05 atau 0,01 maka artinya ada hubungan yang signifikan (berarti) antara pola asuh orang tua dengan perkembangan motorik kasar anak.

\section{SARAN}

Bagi orang tua yang memiliki pola asuh yang baik agar dapat dipertahankan dan bagi orang tua yang memiliki pola asuh yang maksimal agar lebih meningkatkan pengetahuan tentang pola asuh terhadap anak, sehingga tidak menggangu tumbuh kembang anak.

\section{DAFTAR PUSTAKA}

Casmini. 2008. Emotional Parenting Dasar-Dasar Pengasuhan Kecerdasan Emosional Anak. Yogyakrta : P_Idea (Kelompok Pilar Media) Anggota IKAPI

Dariyo, Agoes. 2011. Psikologi Perkembangan Anak Tiga Tahun Pertama. Bandung : PT. Refika Aditama

Dewi, Ismira. 2008. Mengenal Bentuk Pola Asuh Orang Tua. Jakarta : Renika Cipta

Gunarsa, Singgih D. 2008. Psikologi Perkembangan Anak dan Remaja. Jakarta : PT BPK Gunung Mulia

Hana, Nuzulia F. 2016. Hubungan Pola Asuh Orang Tua Dengan Perkembangan Anak Usia Pra Sekolah Di TK Pertiwi 1 Desa Purbowangi Kecamatan Buayan Kabupaten Kebumen. Gombong : STIKES Muhammadiyah Program S1 Keperawatan. Tanggal 19 November 2018

Herlina dan Syaifudin. 2015. Hubungan Pola Asuh Orang Tua Dengan Perkembangan Anak Prasekolah di Pendidikan Usia Dini Aisyiyah Insan Robbani Muntilan. Yogyakarta : Sekolah Tinggi Ilmu Kesehatan Yogyakarta

IDAI. 2013. Mengenal Keterlambatan Perkembangan Umum Pada Anak. Diakses Pada Tanggal 30 Oktober 2018

Iva Norlaila. 2010. Panduan Lengkap Mengajar PAUD. Yogyakarta : Pinus Book Publisher

Kemenkes RI. 2015. Situasi Kesehatan Anak Balita di Indonesia. Jakarta : Kemenkes RI

Jakarta : Renika Cipta

Patmonodewo, Soemiarti. 2008. Pendidikan Anak Prasekolah. Jakrta : Renika Cipta

Setiadi. 2012. Pengaruh Tingkat Pendidikan dan Tipe Pola Asuh Orang Tua Terhadap Perkembangan Psikososial Anak Prasekolah Di Taman KanakKanak. Jurnal Kesehatan AIPTINAKESJATIM. Vol 2 No 1. Suarabaya : STIKES Hang Tuah. Diakses Pada Tanggal 28 Oktober 2018

Soekanto, Soerjono. 2009. Sosiologi Keluarga. Jakarta : Renika Cipta

Soetjiningsih. 2013. Tumbuh Kembang Anak. Jakarta : EGC

Susanto, Ahmad. 2011. Perkembangan Anak Usia Dini : Pengantar Dalam Berbagai Aspeknya. Jakarta : Prenadamedia Group

Widati, A. 2012. Pengaruh Terapi Bermain Terhadap Perkembangan Motorik Halus dan Kognitif Anak Usia Prasekolah (4-5 tahun). Gresik : Universitas Gresik

Yusran. 2014. Pengaruh Pendidikan Kesehatan Terhadap Pengetahuan Dan Sikap Ibu Dalam Mengoptimalkan Pencapaian Tumbuh Kembang Anak Pra Sekolah Di Kecematan Kartasura. Surakarta : Universitas Muhammadiyah Surakarta 